\title{
Self-medication amongst pregnant women in a tertiary care teaching hospital in India
}

\author{
Pooja P. Rangwala ${ }^{1}$, Anushka S. Chokshi ${ }^{1}$, Radhe K. Shah ${ }^{2}$, Ayush S. Thakkar ${ }^{3}$, \\ Yash G. Thakker ${ }^{4}$, Gurusharan H. Dumra*, Yamini N. Trivedi ${ }^{6}$
}

\author{
${ }^{1}$ 3rd Year MBBS Student, AMC MET Medical College, Ahmedabad, Gujarat, India \\ 23rd Year MBBS Student, Smt. NHL Municipal Medical College, Ahmedabad, Gujarat, India \\ ${ }^{3} 3$ rd Year MBBS Student, GCS Medical College, Hospital and Research Centre, Ahmedabad, Gujarat, India \\ ${ }^{4} \mathrm{MBBS}$, AMC MET Medical College, Ahmedabad, Gujarat, India \\ ${ }^{5}$ Department of Pharmacology, ${ }^{6}$ Department of Obstetrics and Gynaecology, AMC MET Medical College and LG \\ Hospital, Ahmedabad, Gujarat, India
}

Received: 27 October 2020

Revised: 07 December 2020

Accepted: 09 December 2020

\section{*Correspondence: \\ Dr. Gurusharan H. Dumra, \\ E-mail: gurusharandumra@gmail.com}

Copyright: (C) the author(s), publisher and licensee Medip Academy. This is an open-access article distributed under the terms of the Creative Commons Attribution Non-Commercial License, which permits unrestricted non-commercial use, distribution, and reproduction in any medium, provided the original work is properly cited.

\begin{abstract}
Background: Self-medication is a popular practice in developing countries where there is no strict regulation of drugs sold in local pharmacies. General public is usually unaware of the adverse effects of drugs used for common illness and continue using them without prescription during pregnancy. This study was carried out to know the extent of self-medication practised by pregnant women and various factors associated with it.

Methods: A questionnaire based, cross-sectional study of pregnant women visiting the OB GYN-OPD of a tertiary care teaching hospital was conducted. 303 eligible subjects were questioned and statistical analysis was carried out.

Results: Total $16.5 \%$ women were found to be self-medicating during pregnancy for common conditions like headache $(26 \%)$, fever (23\%) and common cold (19\%). Odds Ratio between the self-medicating and non-selfmedicating groups for variables like age ( $<25$ years; $\geq 25$ years), education (illiterate; literate) and gestational age $(<20$ weeks; $\geq 20$ weeks) are 1.6, 2 and 1.73 respectively. Women with a history of self-medicating before pregnancy were significantly more likely to continue doing so during pregnancy (p value <0.00001).

Conclusions: A significant proportion of pregnant women have been found to self-medicate without knowing the adverse effects of the drug used. Thus, spreading awareness against this health-predicament is necessary.
\end{abstract}

Keywords: Adverse effect, Pregnancy, Self-medication

\section{INTRODUCTION}

Self-medication as defined by World Health Organisation is the "use of medicinal products by the consumer to treat self-recognized disorders or symptoms, or the intermittent or continued use of a medication prescribed by a physician for chronic or recurring diseases or symptoms."
It is a very popular practice in both urban and rural parts of developing countries like India. ${ }^{2,3}$ Key factors responsible for such widespread self-medication practices, mainly to treat common ailments, include high consultation fees, uncontrolled pharmaceutical flow of prescription drugs, illiteracy and time constraint. ${ }^{4}$ Another factor is the unfaltering trust on the drug recommendation by the store employee at local pharmacies, who is more often than not, under-qualified. 
Following the thalidomide disaster in 1962, a number of studies assessed drug use during pregnancy; both, prescribed as well as self-medicated. ${ }^{5}$

An Indian study carried out in 2012 even showed use of homeopathic and ayurvedic medicines, besides the obvious allopathic drugs used for self-medication by housewives. $^{6}$

A report given by the National coordination centrepharmacovigilance programme of India (NCC-PvPI) on individual case safety reports (ICSRs) due to Over the Counter (OTC) medication during the period 2011-2016 showed that $18.59 \%$ of ICSRs were due to OTCs, $81.28 \%$ due to Scheduled drugs and $0.12 \%$ due to herbal drugs. Among ayurvedic medicines, $65.67 \%$ were serious ICSRs and among homeopathic, $45.83 \%$ were serious ICSRs. ${ }^{7}$

Continuing the use of self-medicated drugs during pregnancy poses a grave risk of adverse effects to both mother and child due to a lack of understanding of drug mechanisms and physiological changes occurring during pregnancy.

This study was undertaken to see the extent of selfmedication during pregnancy in Indian women, and various factors associated with it.

\section{METHODS}

This is a questionnaire based, cross-sectional study on pregnant women who visited the Obstetrics and Gynaecology Outpatient Department (OB GYN-OPD) of LG Hospital, a tertiary care teaching hospital in Ahmedabad, Gujarat, India, from February-April, 2019.

All pregnant women visiting the OB GYN-OPD of the mentioned institute in the mentioned time frame and giving written informed consent were included, while those with comorbidities as well as incompletely filled questionnaires were excluded.

A self-designed questionnaire was used which was validated by the senior faculties of Preventive and Social Medicine, Pharmacology, Obstetrics and Gynaecology department of LG Hospital and AMC MET Medical College. The information obtained from it includes age, educational status, socioeconomic background, obstetric history, awareness of any drug allergy, use of Ayurvedic preparation, practice of self-medication, common conditions self-medicated for (such as fever, cough, nausea and vomiting etc.) and reason for self-medicating (such as prior experience of the disease, advice from pharmacist or store employee etc.)

This study was conducted after the approval of the Institutional Review Board and written informed consent was taken from the participants.
All the participants were asked to fill this questionnaire anonymously in their preferred language (English, Hindi, or Gujarati). If uneducated or unable to fill the questionnaire, it was explained to them and then filled by the researcher. After collecting the data, it was sorted and entered manually into MS Excel and a master chart was prepared. Statistical analysis was carried out for the calculation of proportion, percentages, mean, odds ratio and chi-square test.

\section{RESULTS}

The study population consisted of a total of 303 pregnant women in the age group of 18-44 years, with mean age as $24.5+/-3.9$ years and maximum proportion $(54.5 \%)$ falling in the age group of 18-24 years (Figure 1). Majority of the population was educated till the secondary level (48\%), while $10 \%$ was illiterate (Figure 2 ). The average monthly income of the study population was INR 11,402 with the highest proportion (41.58\%) having the monthly income in the range of INR 500110000. A major proportion of these women (87.5\%) were housewives, while the remaining $12.5 \%$ were employed. Among the participants, $14.5 \%$ were in their $1^{\text {st }}$ trimester of pregnancy, $51.5 \%$ in their $2^{\text {nd }}$ trimester and $34 \%$ in their $3^{\text {rd }}$ trimester. Also, $40.9 \%$ were primigravida and $59.1 \%$ were multigravida.

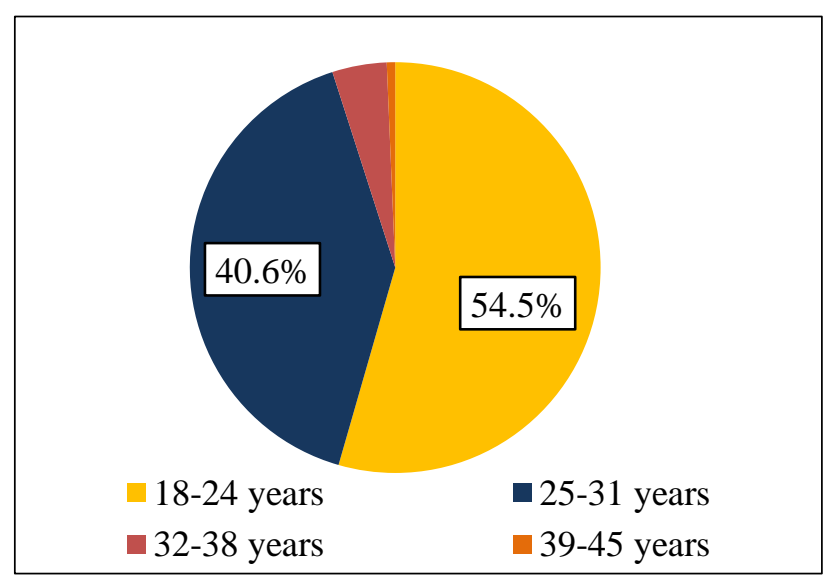

Figure 1: Age distribution of subjects.

Out of 303 participants, $95.7 \%$ did not have any knowledge about drugs to be avoided during pregnancy, and those who did have some idea, were not very clear about it. Despite that, 50(16.7\%) women were selfmedicating during pregnancy, and $94 \%$ of them were unaware of any drug allergies.

The common symptoms for which these pregnant women self-medicated were headache $(26 \%)$, fever $(23 \%)$, common cold $(19 \%)$, cough $(14 \%)$, body-ache $(10 \%)$ etc. (Figure 3). 


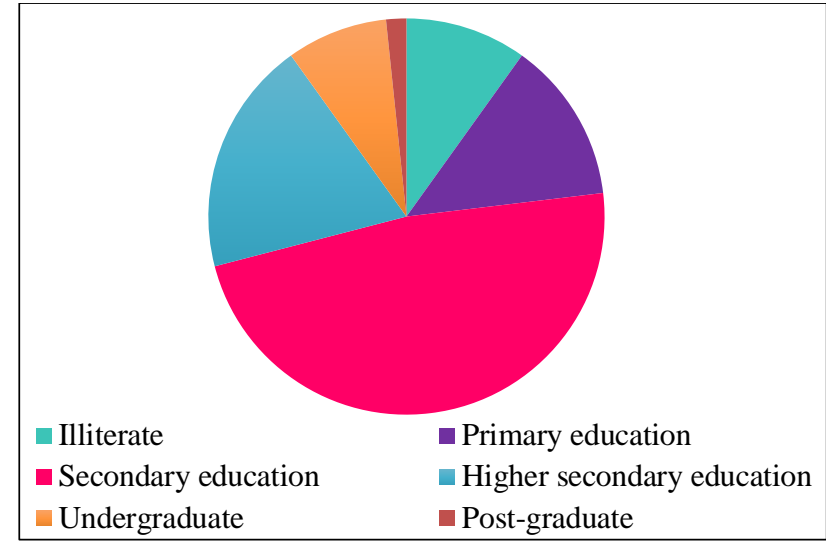

Figure 2: Educational profile of subjects.

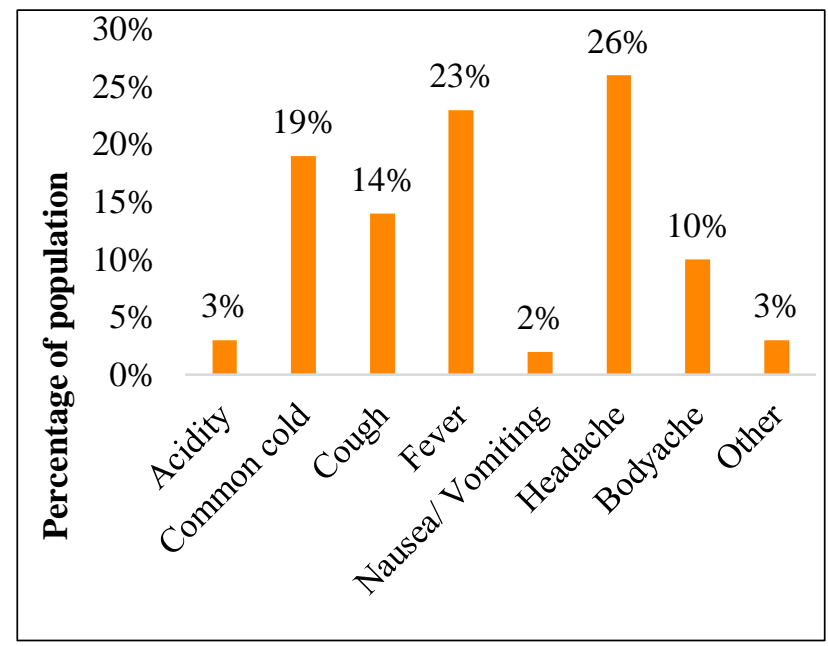

Figure 3: Common symptoms treated by selfmedication.

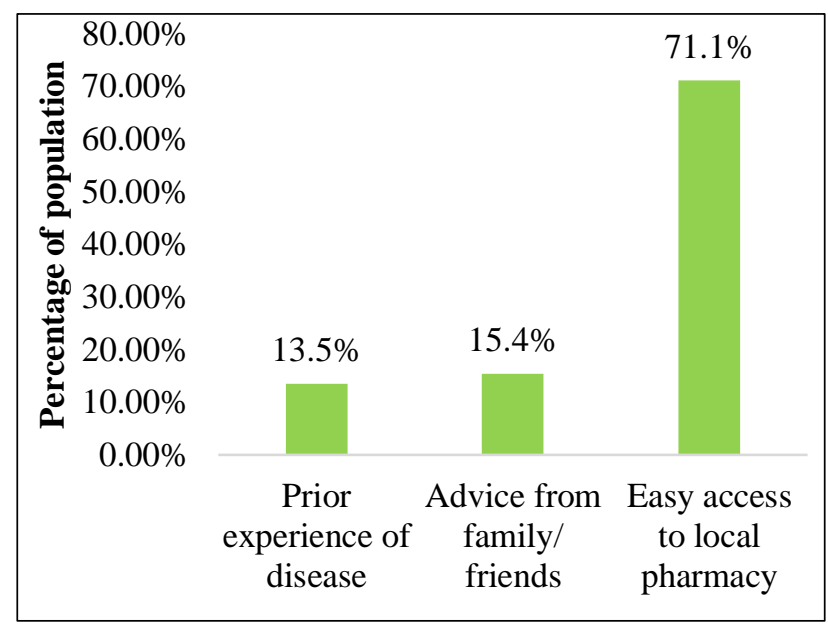

Figure 4: Reason for self-medication.

The main reason for self-medicating (Figure 4) was easy access to local pharmacy $(71.1 \%)$ and the main source of information on the drug used to self-medicate (Figure 5) was the pharmacist or store employee at the local pharmacies $(74.5 \%)$.

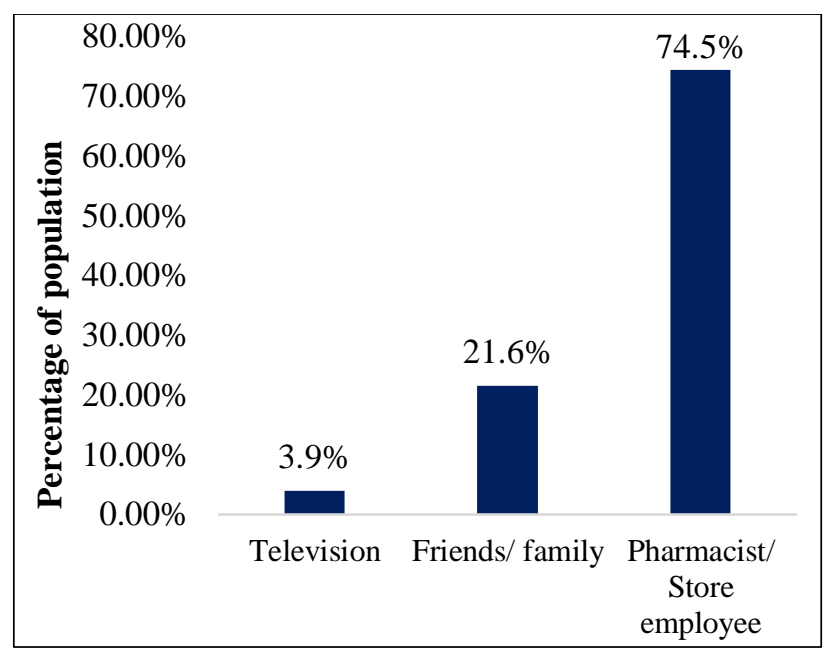

Figure 5: Source of drug information.

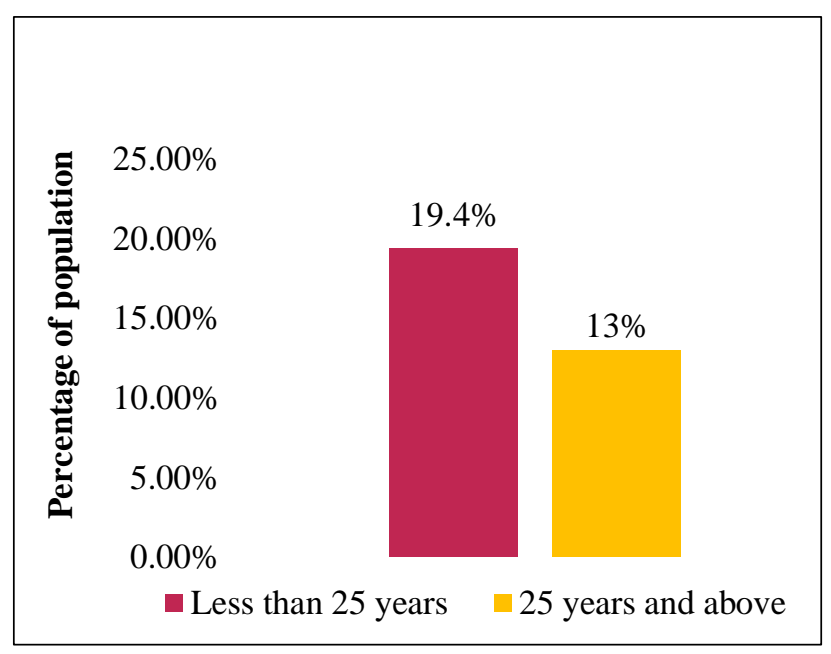

Figure 6: Relation of age and self-medication.

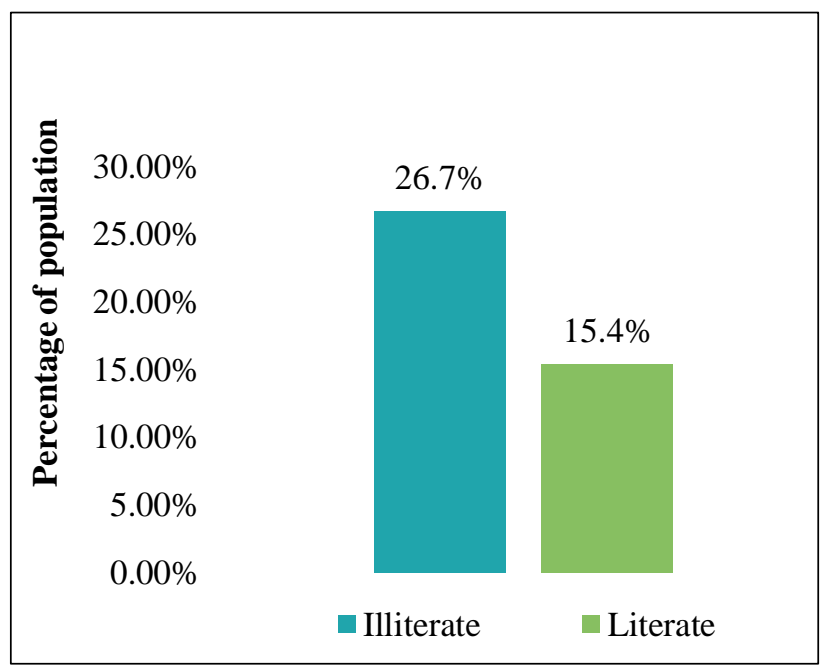

Figure 7: Relation of education and self-medication.

In this study, it was found that younger women $(<25$ years age) were self-medicating more, $(19.4 \%)$ as compared to older women (13\%) (Figure 6); higher 
proportion of illiterate women $(26.7 \%)$ were selfmedicating, as compared to the literate ones $(15.4 \%)$ (Figure 7) and greater proportion of multigravida (19\%) were self-medicating as compared to primigravida (12.9\%) (Figure 8).

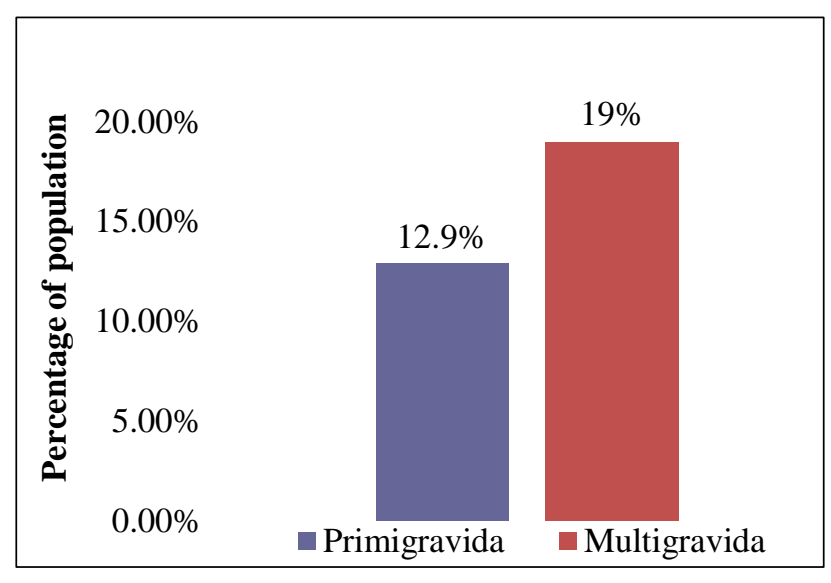

Figure 8: Relation of gravida and self-medication.

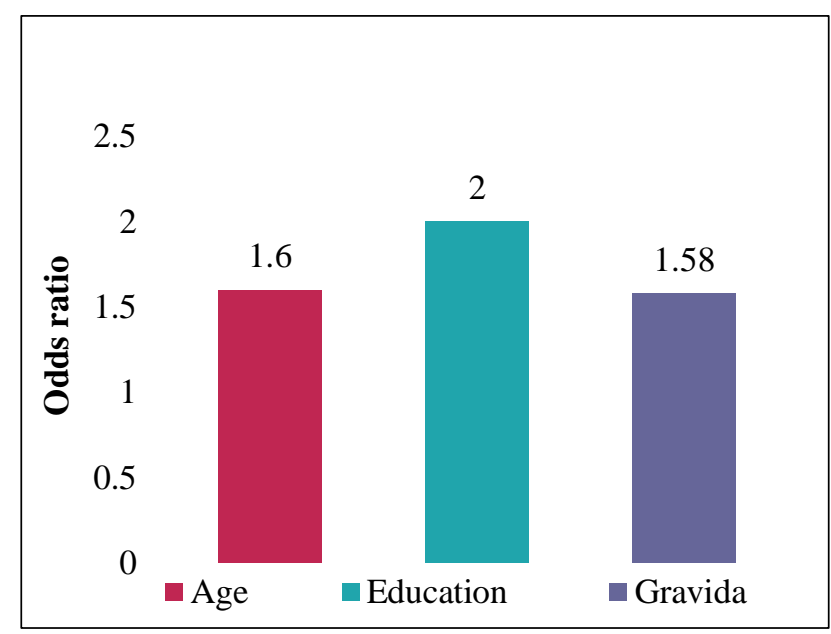

Figure 9: Odds ratio for variables of self-medication.

The odds ratio for the practice of self-medication compared between age groups of $<25$ years and $>=25$ years is 1.6; between illiterate and literate groups is 2 ; between multigravida and primigravida women is 1.58 . Based on this, women who were younger $(<25$ years $)$, illiterate and multigravid were more likely to selfmedicate (Figure 9).

Out of the total subjects, $42.9 \%$ pregnant women had a history of self-medicating before pregnancy. Within this group of women, $36.9 \%$ had continued to do so even during pregnancy. According to the chi-square test, pvalue for this is $<0.00001$ indicating that self-medicating before pregnancy is significantly correlated to its practice during pregnancy.

Besides self-medication, $8.25 \%$ of the population had the habit of consuming tobacco, pan masala and alcohol either alone or in combinations during pregnancy. Also,
$36.6 \%$ of the total population used topical herbal balms for conditions such as headache, body ache and common cold; while $3.3 \%$ used topical analgesics for body ache and oedema which are sold over the counter.

\section{DISCUSSION}

This study was carried out to know and understand the extent of self-medication practiced by pregnant women in a tertiary care teaching hospital of Ahmedabad, a city in west India. Out of the study population, $16.7 \%$ were found to be self-medicating during pregnancy, which is comparable to other studies carried out in Rajshahi city of Bangladesh (12.2\%), Addis Ababa(12.4\%), Goba town of Southeast Ethiopia (15.5\%) and Munich (14.2\%). . $8-10^{-10}$ But, much higher rates were found in an Ethiopian study carried out by Abeje et al and a few Nigerian studies carried out by Yusuff et al, Abasiubong et al and Joseph et al, where the occurrence rates were $36 \%, 63.8 \%$, $72.4 \%$ and $62.9 \%$ respectively. ${ }^{11-14}$

It was found in our study that people often self-medicate to treat minor ailments such as fever, headache, common cold etc., which was also seen in studies carried out by Haque et al and Yusuff et al. ${ }^{8,12}$ This simple habit becomes hazardous when selection of the drug is based on recommendation of an unprofessional, who does not have any idea about its pharmacodynamic and pharmacokinetic properties and its adverse effects on mother and/or foetus; which was often the case.

It was found that younger women, less than 25 years, were more in the habit of self-medicating during pregnancy as compared to older women, which is similar to the Bangladesh study carried out by Haque et al. ${ }^{8}$ This may be either due to lack of experience or seriousness or both.

Education is an important factor that represents the awareness amongst the general population of the harmful effects of self-medication especially during pregnancy. In the current study, practice of self-medication was more among the illiterate, as compared to a study carried out by Sharma et al. ${ }^{15}$ in North India, where graduates were found to self-medicate more.

Another factor which affects this practice is the number of pregnancies. It was found in this study that women tend to become less careful in regards to medicines used after having experienced at least one normal delivery, and hence, multigravid women self-medicate more as compared to primigravid women. A study carried out by Joseph et al in Jos North, Nigeria and another study by Abeje et al in Bahir Dar, Ethiopia showed similar results. ${ }^{8,11,14}$

In this study, very few women had the correct knowledge about drugs to avoid and their side effects (4.3\%). However, the study carried out by Joseph et al, showed a higher proportion $(87.6 \%)$ of women having such 
knowledge, despite having much higher occurrence rate as compared to this study. ${ }^{14}$

The current study showed a strong correlation among women with a history of self-medication and those continuing its practice during pregnancy ( $\mathrm{p}$-value is $0.00001)$.

In this study, pregnant women were found to be selfmedicating less with allopathic medicines (50 women) and instead were using topical herbal preparations more (110 women). A similar study by Abeje et al showed contrasting findings where self-medication using modern medication was more (101 women) and traditional preparations was less (40 women). ${ }^{11}$ Many women may feel that herbal preparations are safer for the child, but the risk associated with using such homemade preparations is very high due to lack of documentation of its adverse effects on mother and foetus. ${ }^{16}$ Although few in number, consumption of harmful substances such as alcohol, tobacco etc. during pregnancy was found in this study as well as in another study carried out by Abasiubong. ${ }^{13}$

On one hand, easy availability of drugs in local pharmacies have been a constant encouragement for this practise of self-medication worldwide. ${ }^{8}$ While, on the other hand, lack of knowledge regarding the harms of self-medicating in general as well as during pregnancy where the damage is to both mother and foetus, is a driving force that prevents people from seeking proper medical help. Controlling pharmaceutical flow is therefore a necessary measure along with creating awareness, so that the problem of self-medication can be dealt with from both ends.

The main limitation of this study was that the type of drugs used to self-medicate were not obtained because of lack of knowledge of the subjects, which stresses on the severity of the problem. Inability to obtain detailed information about composition of herbal products used and inclusion of only those women attending the antenatal clinic during the study period are the other lacunae of this study. Since this was a cross-sectional study, we could not report any adverse drug reactions which may have occurred as a result of self-medication.

Hence, more data needs to be collected on the prevalence of self-medication during pregnancy in both rural and urban parts of our country; as well as adverse effects of drugs self-medicated on the pregnancy outcome.

\section{CONCLUSION}

The occurrence rate for women self-medicating during pregnancy was found to be $16.7 \%$ in this study which was carried out in a tertiary care institute. There is a need to inform, educate and communicate with women of reproductive age regarding the harms of self-medicating during pregnancy without having complete knowledge about the drug used. The current study was performed in an urban setting; the situation could be much worse in rural areas.

Funding: No funding sources

Conflict of interest: None declared

Ethical approval: The study was approved by the Institutional Review Board

\section{REFERENCES}

1. Guidelines for the Regulatory Assessment of Medicinal Products for use in Self-Medication. World Health Organization, 2000. Available from: http://apps.who.int/medicinedocs/pdf/s2218e/s2218e. pdf. Accessed 2019 Nov 1.

2. Kumar V, Mangal A, Yadav G, Raut D, Singh S. Prevalence and pattern of self-medication practices in an urban area of Delhi, India. Med J Dr DY Patil Univ. 2015;8(1):16.

3. Ahmad A, Patel I, Gp M, Balkrishnan R. Evaluation of Self Medication Practices in Rural Area of Town Sahaswan at Northern India. Ann Med Heal Sci Res. 2014;4(2):73-8.

4. Govani KJ, Nimavat K. Evaluation of SelfMedication Practices and its Associated Factors among Urban Population of Ahmedabad City, Gujarat. Natl J Community Med. 2017;8(9):550-3.

5. Irl C, Kipferler P, Hasford J. Drug use assessment and risk evaluation in pregnancy - The PEGASUSproject. Pharmacoepidemiol Drug Saf. 1997;6(SUPPL. 3).

6. Kaushal J, Gupta MC, Jindal P, Verma S. Selfmedication patterns and drug use behavior in housewives belonging to the middle income group in a city in northern India. Indian J Community Med. 2012;37(1): 16

7. Safety Profile of Over-the-Counter Drugs. Newsletter Pharmacovigilance Programme of India (PvPI). 2016;6(16):4-5.

8. Haque U, Khatun $\mathrm{S}$, Amin N, Afrin T, Jannat A, Rashid S, et al. Prevalence and Nature of SelfMedication of Drugs Among Pregnant Women in Rajshahi City, Bangladesh. Eur J Prev Med. 2016;4(6):125.

9. Kebede B, Gedif T, Getachew A. Assessment of drug use among pregnant women in Addis Ababa, Ethiopia. Pharmacoepidemiol Drug Saf. 2009;18(30 March, 2009):462-8.

10. Zewdie T, Azale T, Shimeka A, Lakew AM. Selfmedication during pregnancy and associated factors among pregnant women in Goba town, southeast Ethiopia: A community based cross sectional study. BMC Res Notes. 2018;11(1):1-6.

11. Abeje G, Admasie C, Wasie B. Factors associated with self medication practice among pregnant mothers attending antenatal care at governmental health centers in Bahir Dar city administration, Northwest Ethiopia, a cross sectional study. Pan Afr Med J. 2015;20:276. 
12. Yusuff KB, Omarusehe LD. Determinants of self medication practices among pregnant women in Ibadan, Nigeria. Int J Clin Pharm. 2011;33(5):86875.

13. Abasiubong F, Bassey EA, Udobang JA, Akinbami OS, Udoh SB, Idung AU. Self-medication: Potential risks and hazards among pregnant women in Uyo, Nigeria. Pan Afr Med J. 2012;13:1-8.

14. Joseph BN, Ezie IJ, Aya BM, Dapar MLP. Selfmedication among Pregnant Women Attending Antenatal Clinics in Jos-North , Nigeria. Int J Trop Dis Heal. 2017;21(1):1-7.
15. Sharma R, Kapoor B, Verma U. Drug utilization pattern during pregnancy in North India. Indian $\mathbf{J}$ Med Sci. 2009;60(7):277.

16. Nordeng H, Havnen GC. Use of herbal drugs in pregnancy: A survey among 400 Norwegian women. Pharmacoepidemiol Drug Saf. 2004;13(6):371-80.

Cite this article as: Rangwala PP, Chokshi AS, Shah RK, Thakkar AS, Thakker YG, Dumra GH, et al.

Self-medication amongst pregnant women in a tertiary care teaching hospital in India. Int J Reprod Contracept Obstet Gynecol 2021;10:256-61. 